Témoigner Témoigner. Entre histoire et mémoire

Getuigen Revue pluridisciplinaire de la Fondation Auschwitz

$121 \mid 2015$

Violences radicales en scène

\title{
Jack El-Hai. Le Nazi et le psychiatre
}

Paris, les Arènes, 2013

\section{Colette Gutman}

\section{OpenEdition}

Journals

Édition électronique

URL : https://journals.openedition.org/temoigner/3651

DOI : 10.4000/temoigner.3651

ISSN : 2506-6390

Éditeur :

Éditions du Centre d'études et de documentation Mémoire d'Auschwitz, Éditions Kimé

Édition imprimée

Date de publication : 1 octobre 2015

Pagination : 200

ISSN : 2031-4183

Référence électronique

Colette Gutman, « Jack El-Hai. Le Nazi et le psychiatre », Témoigner. Entre histoire et mémoire [En ligne], 121 | 2015, mis en ligne le 01 octobre 2016, consulté le 04 février 2022. URL : http://

journals.openedition.org/temoigner/3651; DOI : https://doi.org/10.4000/temoigner.3651

Ce document a été généré automatiquement le 4 février 2022

Tous droits réservés 


\title{
Jack El-Hai. Le Nazi et le psychiatre
}

\author{
Paris, les Arènes, 2013
}

\section{Colette Gutman}

\section{RÉFÉRENCE}

Jack El-Hai. Le Nazi et le psychiatre. Paris, les Arènes, 2013, 380 pages

1 À Nuremberg, avant de passer en jugement, chaque prévenu devait être déclaré sain d'esprit et responsable de ses actes. C'est un jeune psychiatre américain, Douglas Kelley, qui a été chargé, entre autres « cas », de celui d'Hermann Göring. Il rentrera aux États-Unis avant la fin du procès, et se suicidera douze ans plus tard, dans sa belle villa californienne avec vue sur le Golden Gate. En entrant dans sa cellule, Göring se considérait comme le plus charismatique et le plus populaire des dirigeants allemands, donnant des conférences de presse, buvant volontiers du champagne avec des soldats américains, posant pour les photographes - et pour l'Histoire. Il est arrivé avec son valet, une douzaine de valises marquées à ses initiales, 1268 reichsmarks en espèces (près d'un million d'euros) et son arsenal médicinal (morphine, codéine, etc.), certain que ce sera l'affaire de quelques jours. Il se retrouve dans une banale cellule, avec une table branlante et une chaise rudimentaire qui s'effondrera immédiatement sous le poids des $135 \mathrm{~kg}$ de graisse accumulés pendant ses années de gloire et de bombances. Il prend enfin conscience de la réalité. Quant à Kelley, il lui revient de maintenir la santé morale de Göring et d'autres détenus nazis jusqu'à ce que leur sort soit déterminé. Il n'ignore rien de la cruauté de son patient, de son narcissisme impitoyable. Son intérêt professionnel porte sur la fascinante cohabitation de traits de caractère opposés admirables et sinistres - : Göring est un homme séduisant, habile, et intelligent d'une part, qui d'autre part a brisé des milliers (des millions) d'existences. Il peut peut-être guider Kelley vers les régions de l'âme humaine qu'il désire ardemment explorer. «Nous n'avons jamais cessé de nous intéresser sur l'existence d'une "personnalité nazie" ", a écrit Annette Wievorka, « Les observations de Kelley, notamment sur Göring, offrent un éclairage passionnant. » Kelley se trouvait-il confronté à une " canaille », un 
"eunuque obèse et inoffensif ", ou à "un simple satellite de Hitler qui passait son temps à courir après les médailles, la gloire et les richesses ? " Kelley était alors adepte inconditionnel d'une discipline développée en 1933 par Alfred Korzyski, qui consistait à convaincre un adversaire en le querellant avec agressivité, tout en l'écoutant attentivement. Sur leurs bancs, les accusés de Nuremberg apparaissaient comme une bande de psychopathes qui auraient «réussi » en parvenant à se saisir de chaque opportunité pour faire progresser leur pouvoir et leur carrière dans une complète indifférence des conséquences: Hermann Göring ou le sadisme pathologique comme voie d'accès à l'élite nazie. Après lui avoir fait passer une batterie de tests et s'être entretenu avec lui pendant des heures, Kelley semble avoir poussé son étude au-delà de sa mission initiale. S'approchant trop près, est-il allé trop loin ? Jusqu'où ? Son suicide douze ans plus tard est-il la réponse à la question? C'est au milieu d'une crise de folie qu'il met fin à ses jours devant sa femme et ses deux jeunes enfants, sous le soleil de Californie, avec une capsule de cyanure. Comme Göring. 